\title{
Comparison of the clinical differences between COVID-19, SARS, influenza, and the common cold: A systematic literature review
}

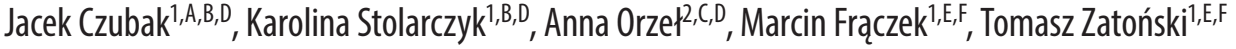 \\ ${ }^{1}$ Department and Clinic of Otolaryngology, Head and Neck Surgery, Wroclaw Medical University, Poland \\ 2 Faculty of Medicine, Medical University of Lublin, Poland \\ A - research concept and design; $\mathrm{B}$ - collection and/or assembly of data; $\mathrm{C}$ - data analysis and interpretation; \\ $D$ - writing the article; $E$ - critical revision of the article; $F$ - final approval of the article
}

\section{Address for correspondence}

Jacek Czubak

E-mail: jacekcz90@gmail.com

Funding sources

None declared

Conflict of interest

None declared

Received on July 16,2020

Reviewed on August 9, 2020

Accepted on 0ctober 29, 2020

Published online on January 30, 2021

\begin{abstract}
Background. This review focuses on the frequency of symptoms in COVID-19 in comparison to SARS, influenza and common cold.
\end{abstract}

Objectives. To evaluate and compare the knowledge about the clinical features, symptoms and differences between patients with COVID-19, SARS, influenza, and common cold. The research can help ear, nose and throat specialists and other health practitioners manage patients during the COVID-19 pandemic.

Material and methods. The biomedical databases used in the study included PubMed and MEDLINE. Statistical analysis using the Z-score test assessed which symptoms were more characteristic of COVID-19 than other viral diseases.

Results. Among individuals with COVID-19, the most frequently reported symptoms were cough (70\%), fever (45\%), muscular pain (29\%), and headache (21\%), whereas sore throat (12\%), and rhinorrhea (4\%) were observed at lower rates. Fever was identified as most frequent in COVID-19 (74\%), appearing at a higher rate in those cases than in influenza (68\%) or the common cold $(40 \%)(p<0.05)$. In comparison to other viral diseases, sore throat was rarely reported in COVID-19 and SARS (12\% and 18\%, respectively) $(p<0.05)$. In influenza and common cold, a cough was identified in $93 \%$ and $80 \%$ of cases $(p<0.05)$. Headache, rhinorrhea, muscular pain, and sore throat were more common in influenza $(91 \%, 91 \%, 94 \%$, and $84 \%$, respectively) and common cold (89\%, 81\%, 94\%, and 84\%, respectively) than in COVID-19 (21\%, 4\%, 29\%, and 12\%, respectively) and SARS (45\%, 12\%, 55\%, and 18\%, respectively) $(p<0.05)$.

Conclusions. The results of the analysis show that a greater number of general symptoms should lead to a diagnosis of influenza or common cold rather than COVID-19.

Key words: influenza, ENT, common cold, COVID-19, SARS

Cite as

Czubak J, Stolarczyk K, Orzeł A, Frączek M, Zatoński T. Comparison of the clinical differences between COVID-19, SARS, influenza, and the common cold: A systematic literature review. Adv Clin Exp Med. 2021;30(1):109-114. doi:10.17219/acem/129573

DOI

10.17219/acem/129573

Copyright

Copyright by Author(s)

This is an article distributed under the terms of the

Creative Commons Attribution 3.0 Unported (CC BY 3.0)

(https://creativecommons.org/licenses/by/3.0/) 


\section{Introduction}

The outbreak of the COVID-19 coronavirus epidemic in the Chinese city of Wuhan and its spread have become a global threat. Severe acute respiratory syndrome coronavirus 2 (SARS-CoV-2) is a $\beta$-coronavirus and the $7^{\text {th }}$ coronavirus to be identified that causes human disease. Overall, SARS-CoV-2 was the $3^{\text {rd }}$ zoonotic human coronavirus of the century. ${ }^{1,2}$ It is spread by human-tohuman transmission via droplets over short distances $(1.5 \mathrm{~m})$, direct contact or (potentially) the gastrointestinal tract. $^{3-5}$ It creates a high risk for virus transmission during ears, nose and throat (ENT) examination, especially during the direct examination of patients' respiratory tract. Moreover, recent studies indicate that ENT specialists are among the groups at a higher risk of exposure to the virus. ${ }^{6}$

COVID-19 is similar to the disease caused by SARS-CoV. Although SARS-CoV-2 is less virulent, it is more infectious and its rapid spread has led to the coronavirus pandemic. ${ }^{7,8}$ According to present clinical data about COVID-19, the symptoms of the disease may affect the upper respiratory tract, similarly to SARS, influenza and common cold. These similarities can pose a major diagnostic problem for any physician.

Every year, the world faces seasonal flu caused by influenza viruses. Three types of influenza viruses affect humans, the most common being type A and type B. ${ }^{9}$ Approximately $30-50 \%$ of cases of common cold are caused by rhinoviruses. The second-most common agents are human coronaviruses (HCoV-OC43, HCoV-HKU1, HCoV-229E, and HCoV-NL63), which account for 10-15\% of cases of this disease. The other causes associated with the common cold are adenoviruses, human respiratory syncytial virus (orthopneumovirus), enteroviruses, and human parainfluenza viruses. ${ }^{10}$

This review focuses on the frequency of symptoms in COVID-19 in comparison to SARS, influenza and common cold. Additionally, the research assesses the incidence of upper respiratory tract symptoms and influenza-like symptoms for the abovementioned viral diseases. To the best of our knowledge, no previous reports have focused on the differential diagnosis between those infectious diseases. The data presented herein are important for ENT specialists, who are often the first-line doctors for patients with upper respiratory tract infection.

\section{Objectives}

The aim of the study was to evaluate and compare information about the clinical features, symptoms and differences between patients with COVID-19, SARS, influenza, and common cold. The research can help ENT specialists and other health practitioners around the world manage patients in the current COVID-19 pandemic.

\section{Material and methods}

The database presented in the study was built from the results of 9 studies published after March 2003. ${ }^{11-19}$ Only articles with data about symptoms of upper respiratory tract infection, such as fever, cough, muscular pain, headache, sore throat, and rhinorrhea, were included. Based on the search strategy, 1729 studies were found in the online database. Then, 1676 articles were excluded after the titles and abstracts were reviewed. The full texts of 53 articles were evaluated. Finally, 9 articles were included in the systematic literature review (Fig. 1).

The data was from 5400 patients with the following diseases: 1347 patients with COVID-19 (25.44\%), 2470 patients with influenza (45.74\%), 282 patients with SARS (5.22\%), and 1274 patients with common cold (23.59\%). Selected clinical presentation of patients with COVID-19, influenza, SARS, and common cold is also presented in Tables 1,2,3.

PubMed was the biomedical database used in the study. To identify the studies for potential review, the following search terms were used: "COVID-19," "SARS," "influenza," "common cold," "upper respiratory symptoms," "influenzalike symptoms," "otolaryngology," "ENT," and "otolaryngological manifestation." The Boolean operators "NOT," "AND" and "OR" were also used in succession to narrow and widen the search.

Only the following symptoms were taken into consideration while comparing the diseases: fever, sore throat, rhinorrhea, headache, cough, and myalgia. Our review was focused on studies about COVID-19, SARS, influenza, and common cold in which upper respiratory tract symptoms and influenza-like symptoms were considered, since they are the most common, mutual shared symptoms. Therefore, a large number of studies focusing on other symptoms (such as gastrointestinal symptoms or cardiologic symptoms) were excluded, which may have led to the omission of some important studies.

The search was limited to publications in English.
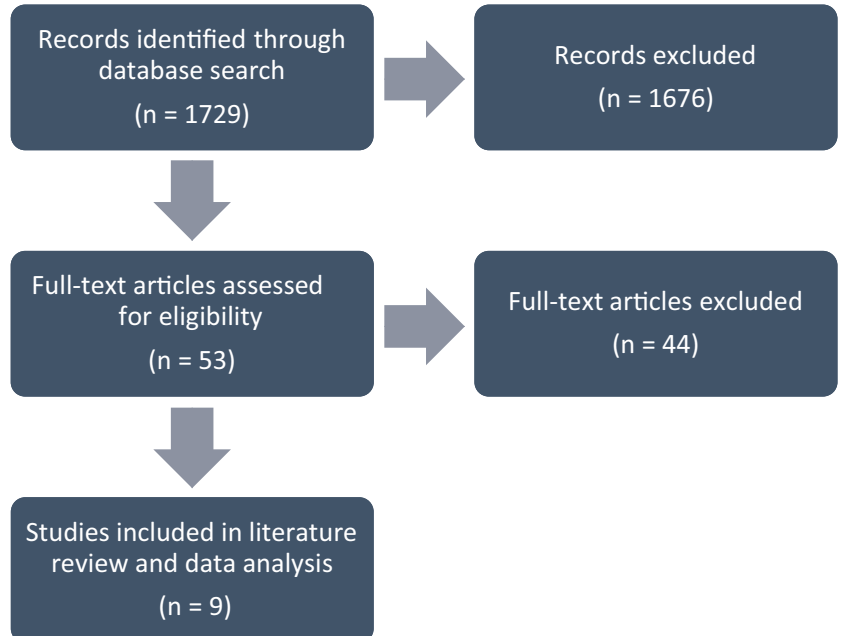

Fig. 1. A flow diagram of the inclusion criteria of studies eligible for the systematic literature review 
Table 1. Selected clinical presentation of patients with COVID-19

\begin{tabular}{|c|c|c|c|c|c|c|c|c|}
\hline \multirow[b]{2}{*}{ Symptoms } & \multicolumn{8}{|c|}{ Study } \\
\hline & $\begin{array}{l}\text { Wang et al. }{ }^{11} \\
(n=138)(\%)\end{array}$ & $\begin{array}{l}\text { Chen et al. }{ }^{12} \\
(n=99)(\%)\end{array}$ & $\begin{array}{c}\text { Huang } \\
\text { et al. }{ }^{13} \\
(n=41)(\%)\end{array}$ & $\begin{array}{l}\text { Kim et al. } .^{14} \\
(n=28)(\%)\end{array}$ & $\begin{array}{c}\text { Jin et al. }{ }^{15} \\
(n=74)(n=577) \\
\text { no Gl symptoms } \\
(n=577)(\%)\end{array}$ & $\begin{array}{c}\text { Jin et al. }{ }^{15} \\
(n=577)(\%)\end{array}$ & $\begin{array}{c}\text { Lechien } \\
\text { et al. }^{16} \\
(\mathrm{n}=417)(\%)\end{array}$ & $\begin{array}{l}\text { Pooled data } \\
(n=1374)(\%)\end{array}$ \\
\hline Age, mean [years] & 56 & 55.5 & 49 & 42.6 & 46.14 & 45.09 & 36.9 & 47.3 \\
\hline $\begin{array}{l}\text { Sex } \\
\text { female } \\
\text { male }\end{array}$ & $\begin{array}{l}63(45.7) \\
75(54.3)\end{array}$ & $\begin{array}{l}32(32) \\
67(68)\end{array}$ & $\begin{array}{l}11(27) \\
30(73)\end{array}$ & $\begin{array}{l}13(46.4) \\
15(53.6)\end{array}$ & $\begin{array}{l}37(50) \\
37(50)\end{array}$ & $\begin{array}{l}283(49) \\
294(51)\end{array}$ & $\begin{array}{l}263(63) \\
154(37)\end{array}$ & $\begin{array}{l}702(51) \\
672(49)\end{array}$ \\
\hline Main symptom & fever & fever & fever & cough & fever & fever & cough & fever \\
\hline Fever & $136(98.6)$ & $82(83)$ & $40(98)$ & $7(25.0)$ & $63(85.14)$ & $482(84)$ & $204(49)$ & $1014(74)$ \\
\hline Sore throat & $24(17.4)$ & $5(5)$ & - & $8(28.6)$ & $6(8.11)$ & $93(16)$ & $33(7.93)$ & $169(12)$ \\
\hline Rhinorrhea & - & $4(4)$ & - & $2(7.1)$ & $2(2.70)$ & $35(6)$ & $18(4.34)$ & $61(4)$ \\
\hline Headache & $9(6.5)$ & $8(8)$ & $3 / 38(8)$ & $7(25.0)$ & $16(21.62)$ & $51(9)$ & $196(45)$ & $290(21)$ \\
\hline Cough & $82(59.4)$ & $81(82)$ & $31(76)$ & $8(28.6)$ & $53(71.62)$ & $382(66)$ & $329(79)$ & $966(70)$ \\
\hline Myalgia & $48(34.8)$ & $11(11)$ & $18(44)$ & $7(25.0)$ & $10(13.51)$ & $61(11)$ & $246(59)$ & $401(29)$ \\
\hline Postnasal drip & - & - & - & - & - & - & $29(6.97)$ & $29(2.11)$ \\
\hline Ear pain & - & - & - & - & - & - & $13(3.13)$ & $13(0.95)$ \\
\hline Nasal obstruction & - & - & - & - & $2(2.70)$ & $35(6.07)$ & $50(12.02)$ & $87(6.33)$ \\
\hline Facial pain/heaviness & - & - & - & - & - & - & $54(12.98)$ & $54(3.93)$ \\
\hline Dyspnea & $43(31.2)$ & $31(31)$ & $22(55)$ & - & - & - & $19(4.57)$ & $115(8.36)$ \\
\hline Diarrhea & $14(10.1)$ & $2(2)$ & $1(3)$ & $3(10.7)$ & $53(71.62)$ & - & $51(12.23)$ & $124(9.02)$ \\
\hline Nausea & $14(10.1)$ & $1(1)$ & - & - & $10(13.52)$ & - & $21(5.03)$ & $46(3.34)$ \\
\hline Vomiting & $5(3.6)$ & $1(1)$ & - & - & $11(14.86)$ & - & $21(5.03)$ & $38(2.76)$ \\
\hline Abdominal pain & $3(2.2)$ & - & - & $1(3.6)$ & - & - & $30(7.19)$ & $34(2.47)$ \\
\hline Dizziness & $13(9.4)$ & - & - & - & - & - & - & $13(0.95)$ \\
\hline
\end{tabular}

Table 2. Selected clinical presentation of patients with influenza and the common cold

\begin{tabular}{|l|c|c|}
\hline \multirow{2}{*}{ Symptoms } & \multicolumn{2}{|c|}{ Study: Monto et al. ${ }^{17}$} \\
\cline { 2 - 3 } & $\begin{array}{c}\text { Laboratory-confirmed } \\
\text { tested negative for } \\
\text { influenza }(\mathrm{n}=2470)(\%)\end{array}$ & $\begin{array}{c}\text { Influenza (common } \\
\text { cold) }(\mathbf{n}=1274)(\%)\end{array}$ \\
\hline Age, mean [years] & 34.8 & 34.5 \\
\hline $\begin{array}{l}\text { Sex } \\
\text { female } \\
\text { male }\end{array}$ & $1223(49.5)$ & $697(54.7)$ \\
\hline Main symptom & $1247(50.5)$ & $577(45.3)$ \\
\hline Fever & myalgia & myalgia \\
\hline Sore throat & $848(68)$ & $1070(84)$ \\
\hline Rhinorrhea & $2075(84)$ & $1032(81)$ \\
\hline Headache & $2248(91)$ & $1134(89)$ \\
\hline Cough & $2248(91)$ & $1019(80)$ \\
\hline Myalgia & $2298(93)$ & $1198(94)$ \\
\hline Nasal obstruction & $2321(94)$ & $1032(81)$ \\
\hline Loss of appetite & $2248(91)$ & $1096(86)$ \\
\hline Weakness & $2272(92)$ & $1198(94)$ \\
\hline
\end{tabular}

Articles that did not address the selected topics, low-quality studies, case reports, and studies based on non-significant cohorts were excluded. The full texts of the remaining high-quality articles were examined and elaborated on.
Table 3. Selected clinical presentation of patients with SARS

\begin{tabular}{|c|c|c|c|}
\hline \multirow[b]{2}{*}{ Symptoms } & \multicolumn{3}{|c|}{ Study } \\
\hline & $\begin{array}{l}\text { Booth et al. }^{18} \\
(n=144)(\%)\end{array}$ & $\begin{array}{l}\text { Lee et al. }^{19} \\
(n=138)(\%)\end{array}$ & $\begin{array}{l}\text { Pooled data } \\
(n=282)(\%)\end{array}$ \\
\hline Age, mean [years] & 45 & 39.3 & 42.15 \\
\hline $\begin{array}{l}\text { Sex } \\
\text { female } \\
\text { male }\end{array}$ & $\begin{array}{l}88(61) \\
56(39)\end{array}$ & $\begin{array}{l}72(52) \\
66(48)\end{array}$ & $\begin{array}{l}160(57) \\
122(43)\end{array}$ \\
\hline Main symptom & fever & fever & fever \\
\hline Fever & 143 (99.3) & $138(100)$ & $281(100)$ \\
\hline Sore throat & $18(12.5)$ & $32(23.3)$ & $50(18)$ \\
\hline Rhinorrhea & $3(2.1)$ & $31(22.5)$ & $34(12)$ \\
\hline Headache & $51(35.4)$ & $31(22.5)$ & $128(45)$ \\
\hline Cough & $100(69.4)$ & $79(57.3)$ & $179(63)$ \\
\hline Myalgia & $71(49.3)$ & $84(60.9)$ & $155(55)$ \\
\hline Nausea & $28(19.4)$ & 27 (19.6) & $55(19.5)$ \\
\hline Vomiting & $28(19.4)$ & 27 (19.6) & $55(19.5)$ \\
\hline Diarrhea & $34(23.6)$ & 27 (19.6) & $61(21.6)$ \\
\hline Dizziness & $6(4.2)$ & $59(42.8)$ & $65(23)$ \\
\hline Dyspnea & $60(41.7)$ & - & $60(21.3)$ \\
\hline Malaise & $45(31.2)$ & - & $45(16)$ \\
\hline Arthralgia & $15(10.4)$ & - & $15(5.3)$ \\
\hline Chest pain & $15(10.4)$ & - & $15(5.3)$ \\
\hline Abdominal pain & $5(3.5)$ & - & $5(1.8)$ \\
\hline
\end{tabular}


The data analysis involved frequency tables with numerical and percentage values, descriptive statistics, and statistical tests. Statistical analysis was performed using IBM SPSS Statistics v. 25 software (IBM Corp., Armonk, USA). The tests involved in the data analysis were the $\chi^{2}$ and Z-score tests. The non-parametric $X^{2}$ test was used to assess the differences in the appearance of symptoms in studied diseases: COVID-19, influenza, SARS, and common cold. The level of statistical significance was set at $\mathrm{p}=0.05$.

The Z-score test was used to compare the results of independent studies with large sample sizes. It was used to compare patients with COVID-19 and patients with other diseases under study in pairs in terms of the frequency of symptom appearance. Such an approach can determine which symptom was more likely to be observed in COVID-19, and can possibly lead to its diagnosis. Each studied disease was compared separately with COVID-19. The level of statistical significance was set at $\mathrm{p}=0.05$.

\section{Results}

The data regarding the symptoms in viral diseases was analyzed and the results are presented as descriptive and percentage values (Table 4). Moreover, the statistical significance was assessed with a p-value $<0.05$. The analyzed cases of patients with viral diseases indicated that the distribution of symptoms was differentiated. Among individuals with COVID-19, the most frequently reported symptoms were fever (74\%), cough $(70 \%)$, muscular pain (29\%), and headache (21\%), whereas sore throat (12\%) and rhinorrhea (4\%) were observed at lower rates (Table 4). Regarding patients with influenza, all of the symptoms were identified in the majority of cases: myalgia (94\%), cough (93\%), rhinorrhea (91\%), headache (91\%), sore throat (84\%), and fever (68\%) (Table 4). In common cold, 94\% of patients endured muscle pain, the most frequent symptom in that disease. Furthermore, $89 \%$ of the patients reported headache, $84 \%$ sore throat, $81 \%$ rhinorrhea, and $80 \%$ cough; however, a fever was reported in only $40 \%$ of cases (Table 4). When it comes to individuals with SARS, fever was the symptom observed most often (100\%). A cough was reported in 179 patients (63\%), headache in 128 (45\%) and rhinorrhea in 34 patients (12\%). On the other hand, sore throat was identified only in $18 \%$ of patients with SARS (Table 4). These results, showing differences in the frequency of symptoms in viral diseases were found to be statistically significant $(\mathrm{p}<0.05$; Table 4 ).

The statistical analysis using the Z-score test allowed us to assess which symptoms were more characteristic of COVID-19 than of other viral diseases. Fever was identified as the most frequent symptom in COVID-19 (74\%), appearing at a higher rate than in influenza (68\%) or common cold $(40 \%)$ ( $\mathrm{p}<0.05)$. On the other hand, $100 \%$ of patients with SARS infection reported having a fever (Table 4). In comparison to the other viral diseases, patients with COVID-19 and SARS rarely reported sore throat $(12 \%$ and $18 \%$, respectively) ( $\mathrm{p}<0.05)$. However, in influenza and in common cold, cough was identified in $93 \%$ and $80 \%$ of patients, respectively $(\mathrm{p}<0.05)$. Headache, rhinorrhea, muscular pain, and sore throat were more common in influenza (91\%, 91\%, 94\%, and $84 \%$, respectively) and in common cold (89\%, 81\%, 94\%, and $84 \%$, respectively) than in COVID-19 (21\%, 4\%, 29\%, and $12 \%$, respectively) or SARS $(45 \%, 12 \%, 55 \%$, and $18 \%$, respectively) ( $<0.05$; Table 4 ). Other symptoms are also presented in Tables 1,2,3.

\section{Discussion}

To the best of our knowledge, this review is the first to compare the upper respiratory tract and influenza-like symptoms in COVID-19, SARS, influenza, and common cold. Knowledge of the frequency of upper respiratory tract symptoms and influenza-like symptoms in COVID-19, SARS, influenza, and common cold could be used in the differential diagnosis.

The clinical classification divides COVID-19 into 4 types based on the severity of the symptoms. The $1^{\text {st }}$ one, the mild type, is defined as having slight clinical symptoms without pneumonia in radiography, which can be asymptomatic or imitating the common cold. ${ }^{3,13,15}$ The $2^{\text {nd }}$ one, the moderate type, is defined as presenting with fever and/or respiratory symptoms, plus pneumonia

Table 4. Comparison of symptom frequency between the studied diseases

\begin{tabular}{|c|c|c|c|c|}
\hline Variable & COVID 19 & Influenza & SARS & Common cold \\
\hline Number of cases & 1374 & 2470 & 282 & 1274 \\
\hline Fever & $1014(74 \%)$ & $848(68 \%)$ & $281(100 \%)$ & $510(40 \%)$ \\
\hline Sore throat & $169(12 \%)$ & 2075 (84\%) & $50(18 \%)$ & $1070(84 \%)$ \\
\hline Rhinorrhea & $61(4 \%)$ & 2248 (91\%) & $34(12 \%)$ & 1032 (81\%) \\
\hline Headache & $290(21 \%)$ & 2248 (91\%) & $128(45 \%)$ & 1134 (89\%) \\
\hline Cough & $966(70 \%)$ & 2298 (93\%) & $179(63 \%)$ & 1019 (80\%) \\
\hline Myalgia & 401 (29\%) & $2321(94 \%)$ & $155(55 \%)$ & $1198(94 \%)$ \\
\hline
\end{tabular}

$p<0.00001$; result are significant at $p<0.05$. 
in radiography, which may resemble influenza. ${ }^{3,13}$ The $3^{\text {rd }}$ one, the severe type, is diagnosed based on dyspnea (a respiratory rate $\geq 30$ times/min), a resting finger oxygen saturation $\leq 93 \%$ and an arterial $\mathrm{PaO}_{2} / \mathrm{FiO}_{2}$ ratio $\leq 300 \mathrm{~mm} \mathrm{Hg}$ $(1 \mathrm{~mm} \mathrm{Hg}=0.133 \mathrm{kPa})$. The last, the critical type, is defined as respiratory failure with shock and multiple organ failure, requiring mechanical ventilation and admission to the intensive care unit (ICU). ${ }^{3,14}$ The last 2 types can imitate SARS.

The analysis of clinical data in the study indicated significant similarities in the frequency of the symptoms fever and cough in infections caused by SARS-CoV $(100 \%$ and $63 \%$, respectively) and SARS-CoV2 (74\% and 70\%, respectively). The results show that it may not be possible to distinguish among the viral diseases under study judging only by the clinical presentation. The study reveals that general symptoms, like headache and myalgia, or nonspecific upper respiratory tract inflammation symptoms, such as sore throat and rhinorrhea, are more likely to be found in patients with influenza or common cold than in patients with COVID-19. Ninety-four percent of patients with both influenza and the common cold reported myalgia, whereas in the case of COVID-19 patients, this symptom was observed in $29 \%$ of cases. The results show that an increased number of general symptoms should lead to a diagnosis of influenza rather than COVID-19. In the case of common cold, symptoms like headache, myalgia, rhinorrhea, and sore throat will appear more likely than fever. As in a study by Monto et al., comparing influenza and common cold, those factors can be used in common cold and COVID-19 for the initial differential diagnosis. ${ }^{17}$ Therefore, a lack of fever and the presence of headache, myalgia, rhinorrhea, and sore throat could suggest a diagnosis of common cold.

Anosmia and gustatory dysfunction are characteristic signs of SARS-CoV-2 infection. Recently published studies have demonstrated that anosmia and hyposmia can appear before the respiratory symptoms of COVID-19, or even as the only sign of the infection. ${ }^{20}$ It should also be pointed out that anosmia and gustatory dysfunction can occur in patients who do not complain of nasal blockage or any other rhinitis symptoms. ${ }^{21}$ That could indicate direct damage from the virus on the olfactory and gustatory receptors. Researchers from South Korea, China, Germany, France, and Italy have found that a significant number of individuals with COVID-19 were affected by hyposmia or anosmia. For example, in a study by Lechien et al., anosmia occurred in $86 \%$ of patients and gustatory dysfunction was present in $88.8 \%$ of patients. ${ }^{16}$ Further, in a study by Klopfenstein et al., anosmia occurred in $47 \%$ of patients and was associated with dysgeusia in $85 \%$ of cases. ${ }^{21}$ Those smell disorders are very rare in SARS or other coronavirus infections. ${ }^{22}$ Therefore, the British Association of Otorhinolaryngology (ENT-UK) includes a loss of the sense of smell in their list of COVID-19 markers of infection. ${ }^{20}$ Lechien et al. also observed that 3\% of COVID-19 patients complained of ear pain, $6.97 \%$ of postnasal drip and $13 \%$ of facial pain/ heaviness. In the other articles analyzed, those symptoms were not found; therefore, these symptoms were not taken into consideration. ${ }^{16}$ However, it has to be considered that asymptomatic and mild infections of SARS-CoV-2 are frequent. That is why a physician should always treat their patients as potentially infected and follow appropriate precautions to avoid the further spread of the virus. Due to the non-specific symptoms presented in COVID-19, patients cannot be diagnosed solely by clinical presentation; only laboratory tests can confirm a diagnosis. The presence of a wide range of general symptoms (headache, rhinorrhea, myalgia, and sore throat) should lead physicians to clinically suspect influenza or common cold rather than COVID-19. This could then guide medical decisions to be made before confirmatory tests are available.

Real-time reverse transcriptase-polymerase chain reaction (RT-PCR) is a specific molecular examination for SARS-CoV-2. It is performed on specimens which are obtained mainly from nasopharyngeal swabs or oropharyngeal swabs, but also from the stool. ${ }^{23,24}$ Wang et al. recommend samples from the lower respiratory tract of the patients (sputum and bronchoalveolar lavage fluid), although nasopharyngeal swab is more commonly used and easier to obtain. ${ }^{24,25}$ Recent studies suggest that chest computed tomography (CT) is a sensitive diagnostic tool for COVID-19 diagnosis with a sensitivity of $97 \%$ in a patient with positive RT-PCR tests. ${ }^{24,26}$ Interestingly, even asymptomatic patients with COVID-19 had radiological changes in their lungs 1 day after exposure, which is also helpful in differential diagnostics. ${ }^{14}$ In influenza, RTPCR and viral culturing have a sensitivity close to $100 \%$, but the turnaround time for a viral culture is 3-10 days compared to $1-8 \mathrm{~h}$ for RT-PCR. ${ }^{9}$ In SARS, RT-PCR is the method of the first choice for detection. ${ }^{27}$

\section{Conclusions}

Although further investigation is required to strengthen the observation made in the present study, our results add some evidence that could be used in the differential diagnosis of COVID-19, SARS, influenza, and common cold.

\section{ORCID iDs}

Jacek Czubak (D) https://orcid.org/0000-0003-0205-1955 Karolina Stolarczyk (D) https://orcid.org/0000-0002-4514-0387 Anna Orzeł (D) https://orcid.org/0000-0002-5908-6967

Marcin Frączek (1) https://orcid.org/0000-0003-0181-122X

Tomasz Zatoński (i) https://orcid.org/0000-0003-3043-4806

\section{References}

1. Zhu N, Zhang D, Wang W, et al; China Novel Coronavirus Investigating and Research Team. A novel coronavirus from patients with pneumonia in China, 2019. NEngl J Med. 2020;382(8):727-733. doi:10.1056/ NEJMoa2001017

2. Zhou M, Zhang X, Qu J. Coronavirus disease 2019 (COVID-19): A clinical update. Front Med. 2020;2:1-10. doi:10.1007/s11684-020-0767-8 
3. Lovato A, de Filippis C. Clinical presentation of COVID-19: A systematic review focusing on upper airway symptoms. Ear Nose Throat. 2020;99(9):569-576. doi:10.1177/0145561320920762

4. Trilla A. One world, one health: The novel coronavirus COVID-19 epidemic. Med Clin (Barc). 2020;154(5):175-177. doi:10.1016/j.medcli. 2020.02.002

5. Wong SH, Lui RN, Sung JJ. Covid-19 and the digestive system. J Gastroenterol Hepatol. 2020;35(5):744-748. doi:10.1111/jgh.15047

6. Boccalatte LA, Larranaga JJ, Perez Raffo GM, et al. Brief guideline for the prevention of COVID-19 infection in head and neck and otolaryngology surgeons. Am J Otolaryngol. 2020;41(3):102484. doi:10. 1016/j.amjoto.2020.102484

7. Guo YR, Cao QD, Hong ZS, et al. The origin, transmission and clinical therapies on coronavirus disease 2019 (COVID-19) outbreak: An update on the status. MilMed Res. 2020;7(1):11. doi:10.1186/s40779020-00240-0

8. Chen J, Qi T, Liu L, et al. Clinical progression of patients with COVID-19 in Shanghai, China. J Infect. 2020;80(5):e1-e6. doi:10.1016/j.jinf. 2020.03.004

9. Paules C, Subbarao K. Influenza. Lancet. 2017;390(10095):697-708 doi:10.1016/S0140-6736(17)30129-0

10. Eccles R. Understanding the symptoms of the common cold and influenza. Lancet Infect Dis. 2005;5(11):718-725. doi:10.1016/ S1473-3099(05)70270-X

11. Wang D, Hu B, Hu C, et al. Clinical characteristics of 138 hospitalized patients with 2019 novel coronavirus-infected pneumonia in Wuhan, China. JAMA. 2020;323(11):1061-1069. doi:10.1001/jama.2020.1585

12. Chen N, Zhou M, Dong X, et al. Epidemiological and clinical characteristics of 99 cases of 2019 novel coronavirus pneumonia in Wuhan, China: A descriptive study. Lancet. 2020;395(10223):507-513. doi:10.1016/S0140-6736(20)30211-7

13. Huang C, Wang Y, Li X, et al. Clinical features of patients infected with 2019 novel coronavirus in Wuhan, China. Lancet. 2020;395(10223): 497-506. doi:10.1016/S0140-6736(20)30183-5

14. Kim ES, Chin BS, Kang CK, et al; Korea National Committee for Clinical Management of COVID-19. Clinical course and outcomes of patients with severe acute respiratory syndrome coronavirus 2 infection: A preliminary report of the first 28 patients from the Korean cohort study on COVID-19. J Korean Med Sci. 2020;35(13):e142. doi:10.3346/jkms. 2020.35.e142

15. Jin X, Lian JS, Hu JH, et al. Epidemiological, clinical and virological characteristics of 74 cases of coronavirus-infected disease 2019 (COVID-19) with gastrointestinal symptoms. Gut. 2020;69(6):1002-1009. doi:10. 1136/gutjnl-2020-320926
16. Lechien JR, Chiesa-Estomba CM, De Siati DR, et al. Olfactory and gustatory dysfunctions as a clinical presentation of mild-to-moderate forms of the coronavirus disease (COVID-19): A multicenter European study. Eur Arch Otorhinolaryngol. 2020;277(8):2251-2261. doi:10.1007/ s00405-020-05965-1

17. Monto AS, Gravenstein S, Elliott M, Colopy M, Schweinle J. Clinical signs and symptoms predicting influenza infection. Arch Intern Med. 2000; 160(21):3243-3247. doi:10.1001/archinte.160.21.3243

18. Booth CM, Matukas LM, Tomlinson GA, et al. Clinical features and short-term outcomes of 144 patients with SARS in the greater Toronto area. JAMA. 2003;289(21):2801-2809. doi:10.1001/jama.289.21.JOC 30885

19. Lee $N$, Hui $D$, Wu A, et al. A major outbreak of severe acute respiratory syndrome in Hong Kong. $N$ Engl J Med. 2003;348(20): 1986-1994. doi:10.1056/NEJMoa030685

20. Pallanti S. Importance of SARs-Cov-2 anosmia: From phenomenology to neurobiology. Compr Psychiatry. 2020;100:152184. doi:10.1016/j. comppsych.2020.152184

21. Klopfenstein T, Kadiane-Oussou NJ, Toko L, et al. Features of anosmia in COVID-19. Med Mal Infect. 2020;50(5):436-439. doi:10.1016/j. medmal.2020.04.006

22. Vaira LA, Salzano G, Deiana G, De Riu G. Anosmia and ageusia: Common findings in COVID-19 patients. Laryngoscope. 2020;130(7):1787. doi:10.1002/lary.28692

23. Singhal T. A review of coronavirus disease-2019 (COVID-19). Indian J Pediatr. 2020;87(4):281-286. doi:10.1007/s12098-020-03263-6

24. Krajewska J, Krajewski W, Zub K, Zatoński T. COVID-19 in otolaryngologist practice: A review of current knowledge. Eur Arch Otorhinolaryngol. 2020;277(7):1885-1897. doi:10.1007/s00405-020-05968-y

25. Wang $Y$, Kang H, Liu X, Tong Z. Combination of RT-qPCR testing and clinical features for diagnosis of COVID-19 facilitates management of SARS-CoV-2 outbreak. J Med Virol. 2020;92(6):538-539. doi:10.1002/ jmv.25721

26. Ai T, Yang Z, Hou H, et al. Correlation of chest CT and RT-PCR testing in coronavirus disease 2019 (COVID-19) in China: A report of 1014 cases. Radiology. 2020;296(2):E32-E40. doi:10.1148/radiol.2020200642

27. Noh JY, Yoon SW, Kim DJ, et al. Simultaneous detection of severe acute respiratory syndrome, Middle East respiratory syndrome, and related bat coronaviruses by real-time reverse transcription PCR. Arch Virol. 2017;162(6):1617-1623. doi:10.1007/s00705-017-3281-9 